\title{
Knowledge, attitude, and practice of medication among Haikou residents
}

\author{
Yu-Xia Wu ${ }^{1}$, Er-Hao Wang ${ }^{2}$, Xiu-Juan Zhao ${ }^{3}$, Fang-Xuan Han ${ }^{1}$, Jin-Gui Zhang ${ }^{1}$, Lei Cui ${ }^{1}$, Jun Chen ${ }^{1}$, \\ Ping-Ping $\mathrm{Wu}^{1}$
}

${ }^{1}$ Hainan General Hospital/Hainan Affiliated Hospital of Hainan Medical University, Haikou, China; ${ }^{2}$ Hainan Maternal and Child Health Hospital, Haikou, China; ${ }^{3}$ School of Public Health, Hainan Medical University, Haikou, China

Contributions: (I) Conception and design: YX Wu, EH Wang; (II) Administrative support: FX Han; (III) Provision of study materials or patients: JG Zhang, L Cui; (IV) Collection and assembly of data: J Chen, PP Wu; (V) Data analysis and interpretation: XJ Zhao; (VI) Manuscript writing: All authors; (VII) Final approval of manuscript: All authors.

Correspondence to: Er-Hao Wang. Pharmacist in charge, Hainan Maternal and Child Health Hospital, Haikou, China. Email: 114703408@qq.com.

\begin{abstract}
Background: Our study aims to explore the knowledge, attitude, and practice (KAP) and its influencing factors of medication among residents in Haikou, the capital city of Hainan Province, and inform the development of interventions to reduce residents' medication errors.

Methods: A cross-sectional questionnaire survey was conducted to investigate the KAP of medication among Haikou residents and its influencing factors from March to September 2019.

Results: A total of 471 valid questionnaires were collected (245 online and 226 offline), with an effective recovery rate of $94.2 \%$. The average score of KAP of medication were $52.2 \pm 13.08,27.34 \pm 8.14$, and $51.54 \pm 9.22$, respectively. The knowledge score reached "good" in the evaluation criteria of the questionnaire, and the attitude and practice scores were "fair". Multiple linear regression analysis revealed the medication knowledge increased with age; a lower education degree was associated with less knowledge and more medication errors, and a higher education level was associated with more access to medication knowledge.

Conclusions: Education on rational drug use should be performed via multiple ways to promote rational drug use and reduce risky medication behaviors, particularly among residents with low education degrees, e.g., drug counseling and guidance, regularly push medication science popularization, public welfare lecture on rational drug use, organize and compile popular science books.
\end{abstract}

Keywords: Medication behavior; the knowledge, attitude, and practice (KAP); rational drug use

Submitted Feb 24, 2021. Accepted for publication Jun 11, 2021.

doi: 10.21037/apm-21-1295

View this article at: https://dx.doi.org/10.21037/apm-21-1295

\section{Introduction}

Drug information has been widely available in TV, newspapers, and social media, including WeChat and Weibo, and an increasing number of people choose to selfmedicate for common diseases. Self-medication behavior is conducive to promoting self-health and controlling the growth of medical costs. However, self-medication in the real world is often risky because of factors including socioeconomic level, traditional cultures, limited medication knowledge, and misguided by false advertising and personal experiences; thus, unsafe drug use damages health can even be life-threatening (1). False self-medication include self-diagnostic error, incorrect drug choice, failing to understand or follow drug package inserts in taking drugs, irrational drug use, unaware of the drug contraindication, disregarding the physiological particularity of the special drug users. The false behaviors will delay the patient's condition, may cause drug-induced damage to the patient, and can also cause drug abuse. The most serious one is antibiotic abuse.

Hainan is a important free trade island of China under 
construction, and Haikou is the province of Hainan. People continue to pay attention to health awareness, and national medical costs are also increasing. In order to control and reduce medical costs, under the guidance of national policies, every regions continue to popularize medical and health knowledge to improve residents' self-care ability. Resident medication is one of the important Content, so it is of significance to the study of KAP in the region. Here we analyzed the knowledge, attitude, and practice (KAP) of medication and its influencing factors among residents in Haikou, the capital city of Hainan Province, China, with an attempt to inform the development of interventions for reducing medication errors among residents and facilitate pharmacists in hospitals to conduct appropriate pharmacy services and public education activities on rational drug use.

We present the following article in accordance with the SURGE reporting checklist (available at http://dx.doi. org/10.21037/apm-21-1295).

\section{Methods}

All procedures performed in this study involving human participants were in accordance with the Declaration of Helsinki (as revised in 2013). The study was approved by the Medical Ethics Committee of Hainan General Hospital (No. Med-Eth-Re[2021] 125) and informed consent was taken from all the patients.

\section{Subjects}

A cross-sectional questionnaire-based survey was conducted between March and September 2019, with permanent residents of Haikou aged 18 years or older as of the study subjects.

\section{Survey methods}

The survey questionnaires were distributed both online and offline. Designated pharmacists distributed the offline version at the prescription pick-up sites of our hospitals. The respondents filled out the questionnaire forms themselves and then collected on-site by the pharmacists. From the WJX survey and research platform, the online questionnaire was pushed to Haikou residents via WeChat.

\section{Questionnaire}

The questionnaire used was the "KAP Questionnaire on Behavioral Risks of Medication among Chinese Residents" developed by the Science and Technology Development Center of the Chinese Pharmaceutical Society. The questionnaire included basic information about residents, their views and opinions on drugs and drug use, frequency of medication, and frequency and importance of attending lectures or other educational activities on drug use.

\section{Quality control for the questionnaire-based survey}

The system prevented more than one submission per internet provider (IP) address during the online survey. For the offline survey, the hard-copy questionnaire forms were distributed and collected on-site. The collected questionnaires were entered into software, during which the quality of the questionnaires was screened. Forms with multiple choices, missing items, and all the same options were excluded.

\section{Evaluation criteria of the results}

In the questionnaire, the degree of agreement or the actual frequency of occurrence was quantified: 0 , unclear; 1 , strongly disagree; 2 , disagree; 3 , neutral; 4 , agree; and 5 , strongly agree. The medication knowledge section consisted of 28 questions, and a higher score showed lower awareness of medication: 28-56, good awareness; 57-84, average awareness; and $85-140$, poor awareness. The medication practice section consisted of 24 questions, and a higher score showed poorer practice: $24-56$, good practice; $49-84$, average practice; and $73-140$, poor practice. The medication attitude section consisted of 11 questions, and a higher score showed better attitude: 11-22, poor attitude; 23-33, average attitude; and 34-55, good attitude.

\section{Statistical analysis}

The data were entered into the EXCEL 2016 and analyzed with the SPSS 22.0 software package. The general information was described using frequency and composition ratios, and the measurement data are presented as $\bar{x} \pm \mathrm{SD}$. Univariate analysis was performed by using independentsamples $t$-test or ANOVA. Multivariate linear regression models were used to calculate regression coefficients to compare the effect of each causal variable on the outcome variables. The potential correlations among different scores were analyzed. A P value of $<0.05$ was considered significantly different.

\section{Results}

A total of 500 questionnaires were distributed, and 471 valid 


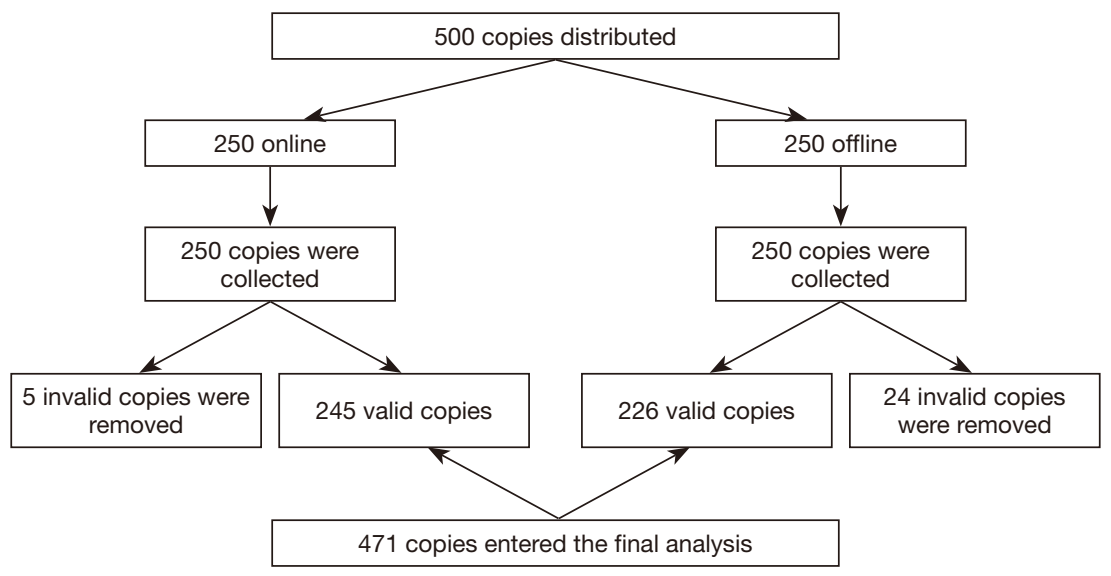

Figure 1 Distribution and collection of the questionnaire forms and the inclusion/exclusion of subjects.

ones (245 online and 226 offline) were collected, with a valid response rate of $94.2 \%$ (Figure 1).

\section{General information of subjects}

Across different occupations, the respondents included 175 males $(37.15 \%)$ and 296 females $(62.85 \%)$, and most of them $(91.72 \%)$ aged $19-49$ years. Their monthly incomes were evenly distributed at three levels: 2,000-4,000 CNY, $4,000-6,000 \mathrm{CNY}$, and $6,000 \mathrm{CNY}$ or more. $84.93 \%$ of the respondents were currently employed, and $77.07 \%$ were urban residents. Bachelor's degree was the most common education degree (48.62\%). Up to $83.44 \%$ of respondents were covered by basic social, medical insurance (BSMI) (Table 1).

\section{KAP scores of medication among Haikou residents}

The univariate analysis of the KAP scores of medication among residents with different gender, ages, monthly income, place of residence, medical insurance status, education level, work status, and occupations are shown in Table 1.

\section{Knowledge scores of medication among Haikou residents}

The average knowledge score of medication among Haikou residents was $52.2 \pm 13.08$, and the overall knowledge score was "good" according to the scoring standard. The scores were rated as "good" in 299 respondents, "average" in 162 respondents, and "poor" in 5 respondents. The differences were statistically significant for the scores of medication knowledge by age, medical insurance coverage, and education level (all $\mathrm{P}<0.05)$.

Practice scores of medication among Haikou residents The average practice score of medication among Haikou residents was $51.54 \pm 9.22$, and the overall knowledge score was "average" according to the scoring standard. The scores were rated as "good" in 165 respondents, "average" in 287 respondents, and "poor" in 17 respondents. The differences were statistically significant for the scores of medication practice by age, medical insurance coverage, education level, employment, and occupation (all $\mathrm{P}<0.05$ ).

\section{Attitude scores of medication among Haikou residents}

The average attitude score of medication among Haikou residents was $27.34 \pm 8.14$, and the overall attitude score was "average" according to the scoring standard. The scores were rated as "good" in 78 respondents, "average" in 286 respondents, and "poor" in 89 respondents. The differences were statistically significant for the scores of medication attitude by education level and occupation (all $\mathrm{P}<0.05)$.

\section{Influencing factors of KAP of medication among Haikou residents}

Values were assigned with the knowledge, practice, and attitude scores as the dependent variables; gender, age, monthly income, place of residence, medical insurance coverage, education level, employment, and occupation as independent variables (Table 2). The results of the multivariate linear analysis are shown in Tables 3-5. 
Table 1 General data and medication risks of subjects in two groups

\begin{tabular}{|c|c|c|c|c|c|c|c|c|c|}
\hline $\begin{array}{l}\text { Demographic } \\
\text { features }\end{array}$ & Group & No. & Percentage - & \multicolumn{2}{|c|}{ Knowledge } & \multicolumn{2}{|c|}{ Practice } & \multicolumn{2}{|l|}{ Attitude } \\
\hline Gender & Male & 175 & 37.2 & $52.76 \pm 13.85$ & 0.472 & $51.50 \pm 9.47$ & 0.939 & $27.51 \pm 8.02$ & 0.724 \\
\hline \multirow[t]{3}{*}{ Age } & 19-34 years & 317 & 67.3 & $52.57 \pm 13.46$ & $0.003^{*}$ & $51.80 \pm 9.33$ & $0.000^{*}$ & $27.38 \pm 8.15$ & 0.051 \\
\hline & $35-49$ years & 115 & 24.4 & $50.91 \pm 10.94$ & & $52.13 \pm 8.81$ & & $28.15 \pm 8.53$ & \\
\hline & 65 years or older & 6 & 1.3 & $35.67 \pm 20.75$ & & $36.50 \pm 7.89$ & & $20.00 \pm 10.04$ & \\
\hline \multirow{3}{*}{$\begin{array}{l}\text { Monthly income } \\
\text { (CNY) }\end{array}$} & Below 1,000 & 34 & 7.2 & $48.71 \pm 17.12$ & 0.271 & $48.50 \pm 12.80$ & 0.135 & $26.47 \pm 7.79$ & 0.265 \\
\hline & $1,001-2,000$ & 36 & 7.6 & $50.44 \pm 13.64$ & & $49.67 \pm 9.61$ & & $28.22 \pm 7.46$ & \\
\hline & $2,001-4,000$ & 134 & 28.5 & $53.46 \pm 12.57$ & & $52.05 \pm 8.66$ & & $26.99 \pm 7.80$ & \\
\hline $\begin{array}{l}\text { Place of } \\
\text { residence }\end{array}$ & Rural areas & 108 & 22.9 & $51.54 \pm 17.29$ & & $51.85 \pm 9.96$ & & $26.41 \pm 8.96$ & \\
\hline \multirow{5}{*}{$\begin{array}{l}\text { Health insurance } \\
\text { coverage }\end{array}$} & Basic social medical insurance & 393 & 83.4 & $52.78 \pm 12.90$ & $0.039^{*}$ & $51.80 \pm 8.96$ & $0.020^{*}$ & $27.53 \pm 8.18$ & 0.097 \\
\hline & Commercial insurance & 14 & 3.0 & $55.71 \pm 13.20$ & & $52.36 \pm 9.74$ & & $26.21 \pm 7.82$ & \\
\hline & Out-of-pocket payment & 31 & 6.6 & $49.19 \pm 12.06$ & & $50.35 \pm 10.89$ & & $26.39 \pm 7.18$ & \\
\hline & $\begin{array}{l}\text { Publicly funded health care } \\
\text { system }\end{array}$ & 20 & 4.2 & $47.65 \pm 11.76$ & & $52.95 \pm 8.13$ & & $29.45 \pm 5.85$ & \\
\hline & Others & 13 & 2.8 & $44.77 \pm 18.83$ & & $43.38 \pm 11.04$ & & $22.00 \pm 10.94$ & \\
\hline Education level & Postgraduate student & 39 & 8.3 & $50.15 \pm 11.02$ & $0.001^{*}$ & $47.03 \pm 11.75$ & $0.000^{*}$ & $29.00 \pm 7.17$ & $0.000^{*}$ \\
\hline \multirow[t]{3}{*}{ Employment } & Currently employed & 400 & 84.9 & $52.08 \pm 13.03$ & 0.704 & $52.09 \pm 9.09$ & $0.009^{*}$ & $27.68 \pm 8.31$ & 0.106 \\
\hline & Retired & 16 & 3.8 & $54.72 \pm 8.76$ & & $48.39 \pm 6.87$ & & $25.78 \pm 6.17$ & \\
\hline & Unemployed/jobless & 53 & 11.3 & $52.23 \pm 14.74$ & & $48.47 \pm 10.17$ & & $25.36 \pm 7.13$ & \\
\hline \multirow[t]{9}{*}{ Occupation } & Factory workers & 35 & 7.4 & $51.69 \pm 11.02$ & 0.319 & $47.60 \pm 6.82$ & $0.029^{*}$ & $27.69 \pm 7.75$ & $0.004^{\star}$ \\
\hline & Company employees & 160 & 34.0 & $53.45 \pm 12.96$ & & $52.51 \pm 8.63$ & & $27.04 \pm 8.19$ & \\
\hline & Government cadres & 33 & 7.0 & $52.76 \pm 9.60$ & & $51.24 \pm 8.84$ & & $28.67 \pm 5.48$ & \\
\hline & Health care workers & 58 & 12.3 & $50.00 \pm 15.70$ & & $52.91 \pm 8.81$ & & $30.88 \pm 8.52$ & \\
\hline & Teachers & 22 & 4.7 & $56.50 \pm 12.04$ & & $54.23 \pm 8.48$ & & $28.05 \pm 7.58$ & \\
\hline & Business managers & 27 & 5.7 & $52.89 \pm 12.16$ & & $53.04 \pm 10.18$ & & $24.96 \pm 9.48$ & \\
\hline & Freelancers & 46 & 9.8 & $49.80 \pm 14.19$ & & $49.54 \pm 9.28$ & & $25.04 \pm 8.48$ & \\
\hline & Students & 19 & 4.0 & $54.68 \pm 14.76$ & & $52.74 \pm 12.15$ & & $29.74 \pm 5.80$ & \\
\hline & Others & 71 & 15.1 & $50.34 \pm 12.63$ & & $49.86 \pm 10.29$ & & $25.89 \pm 8.02$ & \\
\hline Total & & & & $52.20 \pm 13.08$ & & $51.54 \pm 9.22$ & & $27.34 \pm 8.14$ & \\
\hline
\end{tabular}

*, $P<0.05$. 
Table 2 Values assigned for dependent and independent variables

\begin{tabular}{|c|c|}
\hline Variables & Value assignment \\
\hline Age & $19-34$ years $=1,35-49$ years $=2,50-64$ years $=3$, and 65 years and above $=4$ \\
\hline Monthly income & $\begin{array}{l}\text { Below } 1,000 \mathrm{CNY}=1,1,001-2,000 \mathrm{CNY}=2,2,001-4,000 \mathrm{CNY}=3,4,001-6,000 \mathrm{CNY}=4 \text {, and 6,001 and } \\
\text { above } \mathrm{CNY}=5\end{array}$ \\
\hline Education level & $\begin{array}{l}\text { Graduate student }=1 \text {, bachelor's degree }=2 \text {, junior college }=3 \text {, high school/technical secondary school }=4 \text {, } \\
\text { middle school }=5 \text {, and primary school }=6\end{array}$ \\
\hline Employment & Currently employed $=1$, retired $=2$, and unemployed $/$ jobless $=3$ \\
\hline
\end{tabular}

Table 3 Factors influencing the knowledge of medication

\begin{tabular}{|c|c|c|c|c|}
\hline Variables & Parameter estimation & Standardized estimation & $\mathrm{T}$ & $\mathrm{P}$ \\
\hline Gender & -0.854 & 1.268 & -0.674 & 0.501 \\
\hline Age & -1.897 & 0.954 & -1.989 & $0.047^{*}$ \\
\hline Monthly income & 0.780 & 0.604 & 1.292 & 0.197 \\
\hline Health insurance coverage & -1.751 & 0.638 & -2.746 & $0.006^{*}$ \\
\hline Education level & 1.757 & 0.653 & 2.690 & $0.007^{*}$ \\
\hline Employment & 1.780 & 1.148 & 1.551 & 0.122 \\
\hline Occupation & -0.252 & 0.246 & -1.022 & 0.308 \\
\hline$P$ & & $0.01^{*}$ & & \\
\hline
\end{tabular}

${ }^{*}, \mathrm{P}<0.05$.

\section{Factors influencing knowledge of medication among Haikou residents}

Factors influencing medication knowledge were age, medical insurance coverage, and education level, and the rest of the variables were not statistically significant $(\mathrm{P}>0.05)$. Age and medical insurance coverage were negatively correlated with the medication knowledge, while education level showed a positive correlation: the awareness of medication knowledge increased with age, while low education degree was associated with low awareness.

\section{Factors influencing practice of medication among} Haikou residents

Factors influencing the medication practice were medical insurance coverage and education level, and the rest of the variables were not statistically significant $(\mathrm{P}>0.05)$. Medical insurance coverage was negatively correlated with medication, while education level showed a positive correlation. People with a low education degree had more 
Table 4 Factors influencing the practices of medication

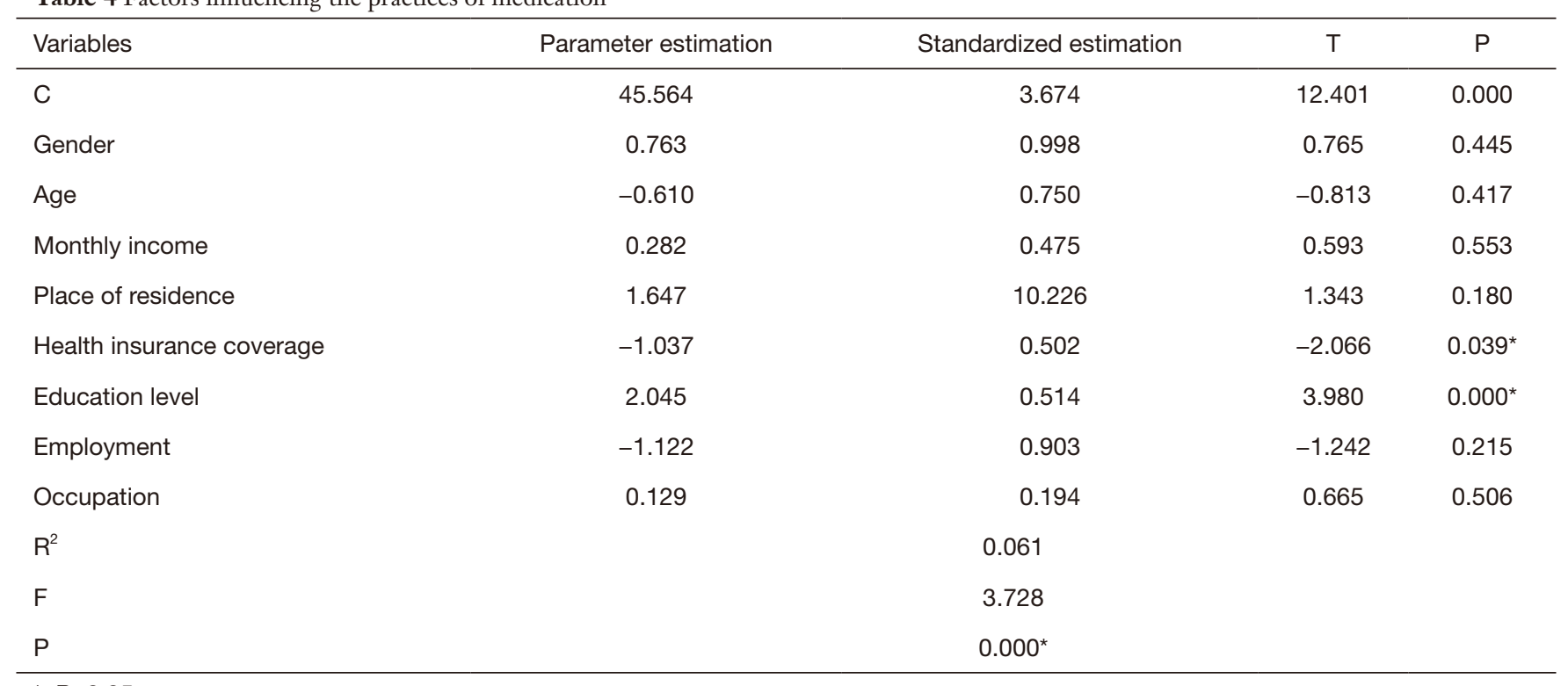

${ }^{*}, \mathrm{P}<0.05$.

Table 5 Factors influencing the attitude of medication

\begin{tabular}{|c|c|c|c|c|}
\hline Variables & Parameter estimation & Standardized estimation & $\mathrm{T}$ & $\mathrm{P}$ \\
\hline Gender & 0.353 & 0.768 & 0.460 & 0.646 \\
\hline Age & 0.132 & 0.578 & 0.228 & 0.820 \\
\hline Monthly income & -0.362 & 0.366 & -0.991 & 0.322 \\
\hline Health insurance coverage & -0.361 & 0.386 & -0.934 & 0.351 \\
\hline Education level & -20.088 & 0.396 & -5.279 & $0.000^{\star}$ \\
\hline Employment & -0.658 & 0.695 & -0.947 & 0.344 \\
\hline Occupation & -0.034 & 0.149 & -0.226 & 0.821 \\
\hline$P$ & & $0.000^{\star}$ & & \\
\hline
\end{tabular}

*, $P<0.05$.

medication problems.

Factors influencing the attitude of medication among Haikou residents

The only factor influencing the medication attitude was education level, and the rest of the variables were not statistically significant $(\mathrm{P}>0.05)$. The education level was negatively correlated with the attitude toward medication, showing people with higher education degrees had more access to medication knowledge. 


\section{Discussion}

\section{Risks associated with the knowledge of medication among Haikou residents}

The poor knowledge of antimicrobials and their resistance in some residents may lead to irrational antibiotic use and drug resistance, resulting in poor clinical outcomes (2). Some respondents did not know which drugs belonged to antimicrobials. For instance, for item 15, "There will not be drug resistance as long as I do not abuse antibiotics myself." Only $49.47 \%$ of the respondents answered correctly. For item 17, "Antibacterial drugs are also known as antiinflammatory agents," $19.32 \%$ of the respondents checked the box "I am not sure". Thus, pharmacy service providers can produce some popular science books and give public lectures on medications to the local residents to increase their awareness of rational drug use and reduce the abuse and misuse of antibacterial medicines.

\section{Risks associated with the practice of medication among Haikou residents}

Only 7.64\% of the respondents "never" disposed of unused or expired medicines in the household trash. Most respondents did not know how to dispose of expired drugs at home. Besides the financial loss to the health care system and patients, expired drugs should be disposed of with care because they contain hazardous substances (3). Also, only $19.96 \%$ of the respondents replied they "never" forgot to use their medicines during the medication period. For patients with chronic diseases requiring longterm medication, medication adherence is closely related to prognosis. Many studies have shown it is necessary to provide pharmacy services to patients with common chronic conditions, including diabetes, hypertension, asthma, hyperlipidemia, chronic pain, rheumatic diseases, or psychiatric disorders (4). Improving medication adherence may have a greater impact on the population's health than discovering any new therapy. Multifactorial solutions to improve medication adherence include efforts to improve patients' understanding of the benefits of medications, and their access to and trust in the hospitals that provide services to them (5). Pharmacists can participate in the management of patients' chronic diseases through pharmacy clinics to provide patients with a full range of medication management to improve patient adherence and promote rational medication use.

\section{Risks associated with the attitude of medication among Haikou residents}

The frequency of residents attending medication safety lectures/medication education activities is low. Up to $23.78 \%$ of the respondents have never participated in such events. With their professional knowledge, pharmacists have valued health care providers of pharmacy services that can improve treatment adherence, clinical outcomes, and health-related quality of life (6). Also, it helps reduce the incidence of adverse reactions. In our current study, 55.84\% of respondents were found to have not participated in any medication counseling services offered by pharmacists. Also, $68.37 \%$ of the respondents believed it was "necessary or extremely necessary" to conduct different forms of education on rational drug use. The respondents agreed more with the medication education activities conducted by hospitals or community health service centers than those conducted by community or neighborhood administrative committees. Although many respondents had not attended any education lectures, they welcomed such events. Therefore, although the respondents fully valued medication education, there is limited access to such events. Health care facilities should further expand their medication education activities and establish more pharmacy learning platforms.

\section{Limitations of the present study}

The questionnaire form used by us consisted of 63 questions, covering 4 dimensions, and was completed by the respondents themselves. Due to the large number of questions designed, some respondents were not patient enough to fill out the questionnaire completely. Some questions have close or similar options, which are difficult for the respondents to select. Some questions require a professional background, and the inconsistent understanding of antibacterial medicines might lead to survey bias. Future research will further update the survey style, optimize the questionnaire design, and increase the sample size to know about the residents' needs more effectively on medication.

At last, We compared to the other regions with the data after 2019, we found that the score of attitude of medication was close to other regions, but the score of knowledge and practice of medication were lower than other regions like Beijing, Chongqing, Sichuan, Xinjiang, Hunan, ShanXi, etc. People are paying more and more attention to the concept of health, but in comparison, Haikou's health knowledge 
and health practices lag behind other regions, which may be related to the relatively backward local education and the insufficient popularity of health education related knowledge. Therefore, we can Start from people's health needs, strengthen the popularization of medical knowledge, so as to improve the reasonable medical behavior of local residents.

\section{Conclusions}

In summary, our current study reflected the current KAP of medication among Haikou residents and will inform the awareness-raising events for improving medication safety. For example, we will make full use of our outpatient pharmacy services and drug consultation offices to provide patients with medication consultation and instructions, medication follow-up visits, and full-course medication management. We will regularly organize lectures on rational drug use to promptly address residents' medication problems and promptly fix their medication errors. We will also promote our pharmacy services and deliver knowledge on rational drug use via our WeChat official account to raise awareness of medication safety among Haikou residents. We will prepare some simple and easy-tounderstand popular science books on safe medication and place them as free reading materials in the waiting areas of our outpatient departments. Also, we will hold special public lectures on rational medication at the prescription pick-up sites. We hope these awareness-raising activities will further promote rational drug use and reduce risky medication behaviors.

\section{Acknowledgments}

Funding: Supported by the Key Project of Science and Technology Communication Innovation Program of National Pharmaceutical Economic Information Network of Chinese Pharmaceutical Association 2019 (Project No.: cmei2019kpyj00106).

\section{Footnote}

Reporting Checklist: The authors have completed the SURGE reporting checklist. Available at http://dx.doi. org/10.21037/apm-21-1295
Data Sharing Statement: Available at http://dx.doi. org/10.21037/apm-21-1295

Conflicts of Interest: All authors have completed the ICMJE uniform disclosure form (available at http://dx.doi. org/10.21037/apm-21-1295). The authors have no conflicts of interest to declare.

Ethical Statement: The authors are accountable for all aspects of the work in ensuring that questions related to the accuracy or integrity of any part of the work are appropriately investigated and resolved. All procedures performed in this study involving human participants were in accordance with the Declaration of Helsinki (as revised in 2013). The study was approved by the Medical Ethics Committee of Hainan General Hospital (No. Med-Eth$\operatorname{Re}[2021] 125)$ and informed consent was taken from all the patients.

Open Access Statement: This is an Open Access article distributed in accordance with the Creative Commons Attribution-NonCommercial-NoDerivs 4.0 International License (CC BY-NC-ND 4.0), which permits the noncommercial replication and distribution of the article with the strict proviso that no changes or edits are made and the original work is properly cited (including links to both the formal publication through the relevant DOI and the license). See: https://creativecommons.org/licenses/by-nc-nd/4.0/.

\section{References}

1. Mamo S, Ayele Y, Dechasa M. Self-medication practices among community of harar city and its surroundings, Eastern Ethiopia. J Pharm (Cairo) 2018;2018:2757108.

2. Jifar A, Ayele Y. Assessment of Knowledge, Attitude, and Practice toward Antibiotic Use among Harar City and Its Surrounding Community, Eastern Ethiopia. Interdiscip Perspect Infect Dis 2018;2018:8492740.

3. Alnahas F, Yeboah P, Fliedel L, et al. Expired medication: Societal, regulatory and ethical aspects of a wasted opportunity. Int J Environ Res Public Health 2020;17:787.

4. Berenguer B, La Casa C, de La Matta M, et al. Pharmaceutical care: past, present and future. Curr Pharm Des 2004;10:3931-46.

5. Brown MT, Bussell J, Dutta S, et al. Medication adherence: 
truth and consequences. Am J Med Sci 2016;351:387-99.

6. Swieczkowski D, Poniatowski P, Merks P, et al. The pharmaceutical care in asthma-Polish and global

Cite this article as: Wu YX, Wang EH, Zhao XJ, Han FX, Zhang JG, Cui L, Chen J, Wu PP. Knowledge, attitude, and practice of medication among Haikou residents. Ann Palliat Med 2021;10(6):6883-6891. doi: 10.21037/apm-21-1295 perspective. Pneumonol Alergol Pol 2016;84:225-31.

(English Language Editor: J. Chapnick) 